\title{
An ergonomic study of postural stress of nurses working in orthopedic wards
}

\author{
Smaranika Goswami, Prasun Haldar and Subhashis Sahu* \\ 'Ergonomics and Occupational Physiology Laboratory, Department of Physiology, University of Kalyani,
}

Kalyani -741 235, Nadia, West Bengal, India

\section{Abstract:}

Mobile It was reported high prevalence of musculoskeletal disorders among nurses. Among the wards, personnel working in Orthopedic wards routinely perform activities that require lifting heavy loads in awkward posture. Challenges faced by them assess patients skillfully and uniquely because orthopedic patients typically present with multiple, complex health problems. During orthopedic patient handling work-related postural strain are most common in health care unit personnel.

This study aims at evaluating the different work-related musculoskeletal strain due to awkward postures, body parts discomforts, and find out some ergonomic solutions to these problems.

Forty nurses working in orthopedic settings of two hospitals were interviewed by modified Nordic Questionnaire to reveal the prevalence of musculoskeletal problems and pain in various regions of the body. BPD Scale was used to identify the intensity of different body parts discomforts. Video recordings and still photographs were taken to evaluate postural stress during different activities were analyzed by OWAS (Ovako working posture analysis) method. Activity analysis chart was also used to represent the duration of different activities of nurses in their respective duty hours.

It was observed that the most physically demanding and postural strenuous task is transferring patient alone. In orthopedics wards different activities like assist patient to walk, changing, other care works are strenuous because as about $90 \%$ of adult patient are over $50 \mathrm{~kg}$ of body weight and due to facture or other problem are unstable. Some ergonomic interventions like assisted lifting, lifting aids, training, etc. are recommended to improve the working conditions and reduce postural strain.

Key Words: Health care unit personnel; Orthopedic ward; Modified Nordic questionnaire; Postural stress.

\section{Introduction}

Nursing profession within the health care sector focused on the care of individuals, families and communities to attain maintain or repose optimal health and quality of life. Work hours in healthcare often involve extended work shifts (longer than 8 hours per day), long work hours (greater than 40 hours per week), on-call work, compulsory overtime, and shift work (work times other than 7:00 A.M. to 6:00 P.M.) to meet the patient care round the clock [1]. Nursing profession is established as a physically and psychologically demanding profession with high prevalence rates of musculoskeletal complaints [2]. The term musculoskeletal disorders represent a significant inflammatory

Corresponding Author: Dr. Subhashis Sahu

Email: skcsahu@yahoo.co.in

(c) 2013 IJOSH All rights reserved. and degenerative condition that affects the muscles, tendons, ligaments, joints, spines, peripheral nerves and supporting blood vessels which consequent ache, pain or discomfort [3, 4].

Work related musculoskeletal disorders (WMSDs) are defined as musculoskeletal disorders that results from a work related event [5]. Work related musculoskeletal disorders are the leading causes of work disability. The most common WMSDs are low back pain, redness in the calf muscle and sciatica, knee and ankle pain, neck, upper limbs and shoulder pain, etc. Studies revealed that nurses suffer most injuries when handling patients and standing or working for long time in awkward posture [6].

Working activities and working condition of the nurses differs from corner to corner around the world [7]. In India, the scenario of healthcare unit is different from that of developed countries. In India, government and private healthcare sectors run parallel. 
Though in India some healthcare organizations have the modern infrastructure facilities but most of the healthcare unit personnel have to work without proper infrastructure. There are always heavy demands for medical services in both the government and private hospitals [8].

It reveals the nature of orthopaedic nursing is unique in nature. Orthopaedic patients refer to people who receive medical and nursing care for musculoskeletal injury or conditions. Modern orthopaedic nursing has transformed itself from the days of Dame Anges Hunt (1867-1948), who is acknowledged as a significant influence on the development of this nursing speciality $[9,10]$. Orthopaedic nurses, like their counterparts in other specialities, have had to respond to changes in populations, lifestyle and environmental factors and fiscal demands. Orthopaedic nurses have been required to adapt their skills to meet the new contingencies of multiple cares.

Nurses working in Orthopaedic wards routinely perform activities that require lifting heavy loads in awkward posture. Daily exposure to heavy job strain increases the risk of low back pain [11]. In addition to physical load, a few studies indicate that psychological factors such as low job satisfaction, high job demand, lack of social support, monotonous work, emotional needs of patients and their family, lack of staff support, etc. may be more related to symptoms of MSDs among nurses [12, 13]. The posture of a nurse can be quantified by several methods with varying levels of accuracy and resource requirements (cost time, efforts and knowledge) [14].

The present study aimed at evaluating the different work-related musculoskeletal strain in nurses working in orthopaedic wards due to awkward postures, body parts discomforts, and find out some ergonomic solutions to these problems.

\section{Methods}

Subjects:

Forty staff nurses were taken randomly as subjects from Orthopaedic wards of two hospitals of West Bengal. The subjects were free from any chronic diseases and having at least one year of experienced in the health care sector. Written consents were taken from the subjects for conducting the study.

Anthropometric variables:

Stature and body weight of the subjects were measured with the help of Martin anthropometric rod and a properly calibrated weighing machine. Body Mass Index (BMI) [15] was calculated from the stature and body weight of the respective subjects.
Nordic questionnaire study:

Personnel working in different orthopaedic settings were interviewed by modified Nordic Questionnaire [16] to reveal the prevalence of musculoskeletal problems and pain in various regions of the body.

Subjective rating of discomfort:

The intensity of pain or different types of discomfort in different body parts were determined by Body Part Discomfort (BPD) scale [17]. This scale is marked as ' 1 ' to ' 10 ' which stands for 'noticeable discomfort' to 'intolerable discomfort' respectively. A 'zero' in the scale means no discomfort at all.

Working posture analysis:

Video recordings and photographs of the subjects were taken during their different activities. Ovako working posture analysis system (OWAS) were applied [18] to evaluate postural stress of the nursing staffs.

Statistical analysis:

Data were expressed as mean \pm standard deviation.

\section{Results}

Table 1 represents the physical profile such as height, weight of the nurses of two Orthopaedic wards. According to World Health Organization [19] the normal range of BMl value is 18.5-24.99 $\mathrm{kg} / \mathrm{m}^{2}$. The calculated BMl value of the nurses was found to be within the normal range.

Table 1 Physical profile of the staff nurses of orthopaedic wards.

\begin{tabular}{|c|c|c|c|}
\hline $\begin{array}{c}\text { Age } \\
\text { (years) }\end{array}$ & $\begin{array}{c}\text { Height } \\
(\mathrm{cm})\end{array}$ & $\begin{array}{c}\text { Weight } \\
(\mathrm{kg})\end{array}$ & $\begin{array}{c}\mathrm{BMI} \\
\left(\mathrm{kg} / \mathrm{m}^{2}\right)\end{array}$ \\
\hline $27.18 \pm 4.1$ & $161.06 \pm 8.00$ & $57.75 \pm 9.6$ & $22.16 \pm 2.52$ \\
\hline$(22-40)$ & $(144.8-176)$ & $(44-78)$ & $(17.02-28.65)$ \\
\hline
\end{tabular}

Table 2 characterizes pain in different body parts of the staff nurses. From the above table, it can be seen that low back has the highest complaints of pain followed by neck and knee among the nurses of the orthopaedic wards which accounts for $47.75 \%$, $27.5 \%$ and $20 \%$ respectively.

In a nursing study [20], the prevalences of low back, shoulder, neck and arm pain in the previous month were found to be $54.7 \%, 42.8 \%, 31.3 \%$ and $18.6 \%$ respectively. Larese and Fiorito [21] found that $48 \% \mathrm{GH}$ and $33 \%$ OD nurses reported back pain due to work, 29.4 and $16.1 \%$ respectively have had X-ray or orthopaedic examinations, $19 \cdot 2 \%$ and $9 \cdot 1 \%$ had been absent from work because of back pain. In another study among nurses in India [22] the occurrences of symptoms of the neck 
Goswami S et al / International Journal of Occupational Safety and Health, Vol 3. No 1 (2013) 26 - 31

pain, shoulder pain, hand pain and knee pain were found to be very high. It was reported that $73 \%$ of nurses complained about pain feeling after returning back home and $21 \%$ during work [22].

Table 2 Complaints about pain in different body parts of the nurses

\begin{tabular}{|c|c|c|}
\hline Pain in different body parts & $\begin{array}{c}\text { No. of subjects } \\
(\mathrm{N}=4 \mathbf{0})\end{array}$ & $\begin{array}{c}\text { Percentage } \\
(\%)\end{array}$ \\
\hline Low back pain & 19 & 47.5 \\
\hline Neck pain & 11 & 27.5 \\
\hline Knee pain & 8 & 20 \\
\hline Shoulder pain & 7 & 17.5 \\
\hline Wrist pain & 6 & 15 \\
\hline Leg pain & 6 & 15 \\
\hline Calf muscle pain & 5 & 12.5 \\
\hline Ankle pain & 5 & 12.5 \\
\hline Whole body pain & 4 & 10 \\
\hline Upper back pain & 3 & 6.67 \\
\hline Arm pain & 2 & 5 \\
\hline Hip/Buttock pain & 2 & 5 \\
\hline
\end{tabular}

Figure 1 Body Parts Discomfort (BPD) scaling of different body parts of nurses in orthopaedic wards.

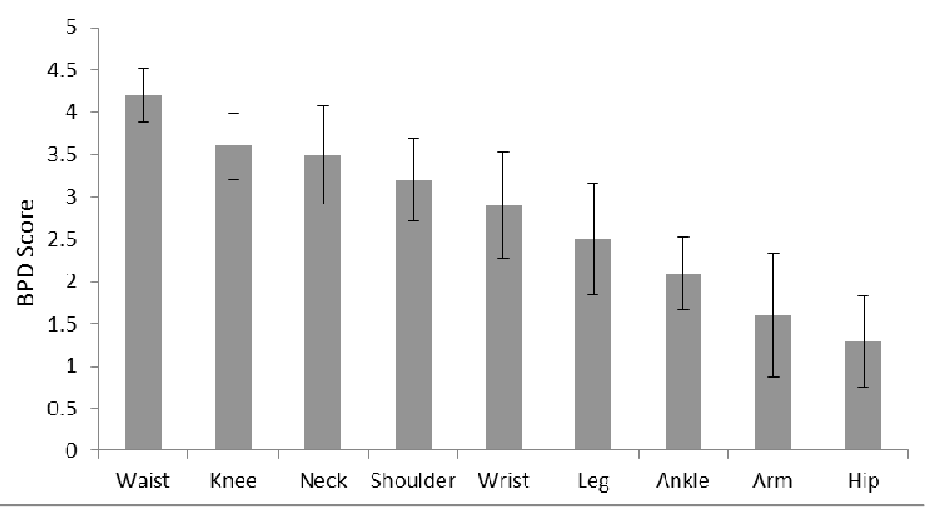

Figure 1 depicts score of Body Parts Discomfort (BPD) scale of nurses. Waist was found to be the most affected body part among nurses of the orthopaedic wards in which the mean BPD score was above $4(4.2 \pm 0.312)$. Result shows that the mean score of BPD was also higher in body parts like knee, neck and shoulder.

Vieira et al., [23] found that among 23 orthopaedic nurses low back scored the most (4.6) for body parts discomfort. Discomfort in low back, neck, knee, leg, shoulder and ankle are the most common among nurses [24]. In another study of 111 workers (64 welders and 47 nurses) from a steel company and a hospital the low back discomfort score was found to be $5 \pm 3$ on a 10 point scale [25].

Table 3 shows that body parts discomfort were found to be higher in tasks like changing body position of patients, transfer of patients, saline infusion, blood sampling and injecting medicine, dressing help and eating help. Mean BPD score of the body parts like waist, neck and shoulder were found to be the most in changing body position of patients. Knee discomfort score was the most in patient transfer activity.

Table 3 Activity oriented Body Parts Discomfort (BPD) scaling of four most affected body parts of nurses.

\begin{tabular}{|l|c|c|c|c|}
\hline \multirow{2}{*}{$\begin{array}{l}\text { Type of tasks performed } \\
\text { by the nurses }\end{array}$} & \multicolumn{4}{|c}{ BPD score } \\
\hline & Waist & Knee & Neck & Shoulder \\
\hline $\begin{array}{l}\text { Changing body position } \\
\text { of patients }\end{array}$ & $4.5 \pm 0.34$ & $2.5 \pm 0.3$ & $3.8 \pm 0.45$ & $4.2 \pm 0.5$ \\
\hline Patient transfer & $3.8 \pm 0.2$ & $3.8 \pm 0.8$ & $2.8 \pm 0.28$ & $2.6 \pm 0.18$ \\
\hline Saline infusion & $4.1 \pm 0.46$ & $3.1 \pm 0.2$ & $2.5 \pm 0.72$ & $2.8 \pm 0.2$ \\
\hline $\begin{array}{l}\text { Blood sampling and } \\
\text { injecting medicine }\end{array}$ & $3.5 \pm 0.65$ & $3.5 \pm 0.24$ & $2.6 \pm 0.3$ & $2.2 \pm 0.62$ \\
\hline Bed making & $3.5 \pm 0.3$ & $2.8 \pm 0.35$ & $3.2 \pm 0.46$ & $3.3 \pm 0.1$ \\
\hline \begin{tabular}{l} 
Tube feeding \\
\hline Medicine preparation
\end{tabular} & $2.2 \pm 0.8$ & $2.6 \pm 0.58$ & $1.8 \pm 0.8$ & $1.8 \pm 0.7$ \\
\hline Medical measurement & $3.8 \pm 0.68$ & $3.6 \pm 0.49$ & $2.3 \pm 0.55$ & $2.6 \pm 0.76$ \\
\hline Dressing help & $3.9 \pm 0.48$ & $2.8 \pm 0.6$ & $3.6 \pm 0.2$ & $3.3 \pm 0.4$ \\
\hline Assist patients in walking & $2.4+0.28$ & $1.9+0.5$ & $2.6+0.9$ & $2.5+0.9$ \\
\hline $\begin{array}{l}\text { Fixing/ modify the plaster } \\
\text { or orthopaedic device }\end{array}$ & $3.2+0.21$ & $2.7 \pm 0.4$ & $2.6 \pm 0.3$ & $3.3 \pm 0.9$ \\
\hline $\begin{array}{l}\text { Eating help } \\
\text { Record and documenta- } \\
\text { tion keeping }\end{array}$ & $2.0 \pm 0.8$ & $2.6 \pm 0.67$ & $2.1 \pm 0.86$ & $1.5 \pm 0.3$ \\
\hline $\begin{array}{l}\text { Discussion with } \\
\text { doctors }\end{array}$ & $1.8 \pm 0.3$ & $2.1 \pm 0.8$ & $1.1 \pm 0.3$ & $1.2 \pm 0.5$ \\
\hline & $3.8 \pm 0.2$ & $3.2 \pm 0.85$ & $3.5 \pm 0.64$ & $4.1 \pm 0.7$ \\
\hline
\end{tabular}

Table 4, reveals OWAS based postural analysis of the different work activity of the nurses of orthopaedic wards. The postural analysis result exposes that the most awkward posture was adopted by the nurses in patient transfer activities. OWAS action level was found to be 4 in the above stated activity and corrective actions should be done immediately for improving posture. In activity like, bed making, dressing help, eating help, saline infusion and body position change/ massageing, etc. of the patients the OWAS action level scored 3 in which the correction action should require as soon as possible.

\section{Discussion}

Nurses perform a wide range of clinical and non-clinical functions necessary to the delivery of health care and musculoskeletal disorders (MSDs) represent a significant problem among nurses [22]. Silverstein et al., [26] reported repetitious movement, awkward postures and high force levels 
Table 4 Posture analysis of different working activities of the nurses by OWAS method

\begin{tabular}{|c|c|c|c|c|}
\hline Types of work & Stick diagram & OWAS score & $\begin{array}{l}\text { Action } \\
\text { category }\end{array}$ & Explanation \\
\hline Bed making & & $2,1,4,1$ & 3 & Correction action should be done as soon as possible \\
\hline $\begin{array}{l}\text { Dressing help/fixing } \\
\text { aids }\end{array}$ & & $2,1,4,1$ & 3 & Correction action should be done as soon as possible \\
\hline Eating help/assist & & $2,1,4,1$ & 3 & Correction action should be done as soon as possible \\
\hline $\begin{array}{l}\text { Record and documen- } \\
\text { tation keeping }\end{array}$ & & $1,1,1,1$ & 1 & No action required \\
\hline Medicine preparation & & $1,1,2,1$ & 1 & No action required \\
\hline $\begin{array}{l}\text { Assist patients in } \\
\text { walking }\end{array}$ & & $1,1,2,1$ & 1 & No action required \\
\hline $\begin{array}{l}\text { Blood sampling and } \\
\text { injecting medicine }\end{array}$ & & $2,1,2,1$ & 2 & Corrective action required in the near future \\
\hline Saline infusion & & $2,1,4,1$ & 3 & Correction action should be done as soon as possible \\
\hline $\begin{array}{l}\text { Fixing plaster/modify } \\
\text { orthopaedic devices }\end{array}$ & & $2,1,2,1$ & 2 & Corrective action required in the near future \\
\hline Tube feeding & & $2,2,2,1$ & 2 & Corrective action required in the near future \\
\hline $\begin{array}{l}\text { Body position change/ } \\
\text { massage }\end{array}$ & & $2,2,4,1$ & 3 & Correction action should be done as soon as possible \\
\hline Patient transfer & & $4,2,4,3$ & 4 & Corrective actions for improvement required immediately \\
\hline
\end{tabular}


as the three primary risk factors that have been associated with WMSDs.

Seventy five percent of the low back disorders were classified as sprains, strains and tears and approximately $70 \%$ of these resulted from overexertion in lifting and shifting of patients, pushing or pulling heavy trolley, carrying heavy weights, etc. (Alberta Human Resources and Employment, 2003). Bending, twisting and making forceful movements were shown to be related to having low back pain [27].

In our present study it was revealed that the work related musculoskeletal disorders (WMSDs) affects different body parts of the nurse. Pain complaint in the low back region (47.75\%) was found to be most severe among nurses of the orthopedics wards with the highest prevalence of body parts discomfort in waist region. Patient transfer tasks have the highest OWAS action level that required immediate improvement. Different work related awkward postures adopted by the nurses that means deviation of body posture from its neutral position (such as bent, twist back, a bent wrist or arms raised above the head), handling of various load during work and sometimes poor working conditions were thought to be responsible for the WMSDs. These are sometimes imposed by unergonomic design in workplace and working equipment. Daraiseh et al., [28] reported that MSDs in various body regions of nurses were influenced by stressful working conditions. It was reported that low back pain of the nurses was not only associated with physical factors but also with a complex interaction of working conditions. [8, 22, 29].

\section{Conclusion}

Among the wards, nurses working in Orthopaedic wards routinely perform activities that require lifting heavy loads in awkward posture. Transferring patient alone and body position changing of the patients were set up to be the most physically challenging and postural strenuous task. In orthopaedics wards different activities like assist patient to walk, changing, other care works are strenuous because as about $90 \%$ of adult patient are over 50 $\mathrm{kg}$ of body weight and due to facture or other problem are unstable. So, some ergonomic interventions like proper distribution of activities, assistive lifting, using of lifting aids and training for safe lifting and carrying is recommended.

\section{Acknowledgement}

The authors are grateful to the nurses who volunteered for the study and gladly accepted the inconvenienced involved in it. Dr. S. Sahu author acknowledge the financial assistance from Personal Research Grant of University of Kalyani and Mr. P. Halder acknowledge the University Research Fellowship from University of Kalyani.

\section{Reference}

1. Caruso, CC and Waters, TR. A review of work schedule issues and musculoskeletal disorders with an emphasis on the healthcare sector. Industrial Health 2008. 46: 523-534.

2. Menzel, NN. Back pain prevalence in nursing personnel: measurement issues. AAOHN Journal 2004. 52: 54-65.

3. Punnett, L and Wegman, DH. Work related musculoskeletal disorders: the epidemiologic evidence and the debates. Journal of Electromyography and Kinesiology 2004. 14: 1323.

4. Smith, DR. Myung Ki, JC. Kim, J and Yamagata, Z. Musculoskeletal disorders among staff in South Korea's largest nursing home. Environ Health and Prev Med. 2003. 8: 2328.

5. Salik, $Y$ and Ozcan, A. Work related musculoskeletal disorder: A survey of physical therapists in Lzmir-Turkey. BMC Musculoskeletal disorder 2004, 5:27.

6. Trinkoff AM. Lipscomb, JA and Geiger-Brown, J. Musculoskeletal problems of the neck, shoulder and back and functional consequences in nurses. American Journal of Industrial Medicine 2002. 41:170-178.

7. Simon, M. Tackenberg, P. Nienhaus, A. Estryn-Behar, M. Conway, PM and Hasselhorn, HM. Back or neck-painrelated disability of nursing staff in hospitals, nursing homes and home care in seven countries - results from the European NEXT-Study. International Journal of Nursing Studies 2008. 45: 24-34.

8. Sahu, S. Goswami, S. Haldar, P and Sett, M. An ergonomic evaluation of tasks of healthcare unit personnel in different shifts in general hospitals in West Bengal. International Journal of Occupational Safety and Health 2012. 2: 14-22.

9. Carter, M. The early days of orthopaedic nursing in the U KAgnes Hunt and Baschurch. Journal of Orthopaedic Nursing 2000a. 4: 55-58.

10. Carter, M. From open air to high-tech care: Orthopaedic nursing at Oswestry 1992-2000. Journal of Orthopaedic Nursing 2000b. 4: 175-178.

11. Josephson, M. Lagerstrom, $M$ and Hagberg, $M$. Musculoskeletal symptoms and job strain among nursing personnel: a study over a three year period. Occup Environ Med 1997. 54: 681-685. 
12. Alexopoulos, EC. Burdorf, A and Kalokerinou, A. Risk factors for musculoskeletal disorders among nursing personnel in Greek Hospital. Int. Arch. Occup. Environ. Health 2003. 76: 289-294.

13. Lagerstrom, $M$. Wenemark, $M$ and Hagberg, $M$. Occupational and individual factors related to musculoskeletal symptoms in five body regions among Swedish nursing personnel. Int. Arch. Occup. Environ. Health 1995. 68: 27-35.

14. Burdorf, A. Rossignol, M. Fathallah, FA. Snook, SH and Herrick, RF. Challenges in assessing risk factors in epidemiological studies on back disorders. American Journal of Industrial Medicine 1997. 32: 142-152.

15. Weisell, RC. Body mass index as an indicator of obesity. Asia Pacific Journal of Clinical Nutrition 2002. 11 (Suppl.): S681-S684.

16. Kourinka, I. Jonsson, B. Kilbom, A. Vinterberg, $H$. Biering-Sorenson, F. Andersson, $G$ and Jorgenson, K. 'Standardised Nordic questionnaire for the analysis of musculoskeletal symptoms'. Applied Ergonomics 1987. 18: 233-237.

17. Jacquelin, LR. Drury, $G$ and Richard, LB. A field methodology for the control of musculoskeletal injuries. Appl. Ergon. 1994. 25: 3-16.

18. Kulagowska, E. Musculoskeletal system load in operating room nurses and its determinants. Medycyna Pracy 2009. 60: 187-195.

19. World Health Organization. Health Factors in working under conditions of heat stress. WHO Technical Report Series 1969. 412: Geneva.

20. Ando, S. Ono, Y. Shimaoka, M. Hiruta, S. Hattori, Y. Hori, F and Takeuchi, Y. Association of self-estimated workloads with musculoskeletal symptoms among hospital nurses. Occupational and Environmental Medicine 2000. 57: 211216.

21. Larese, F and Fiorito, A. Musculoskeletal disorders in hospital nurses: a comparison between two hospitals. Ergonomics 1994. 37: 1205-1211.

22. Goswami S. Haldar P. Sahu S. (2011): Study on health problems and postural stress of nurses working in hospitals of Burdwan district. Journal of Environmental Physiology, 3 (1\&2), $25-33$.
23. Vieira, ER. Kumar, S. Coury, HJCG and Narayan, Y. Low back problems and possible improvements in nursing jobs. Journal of Advanced Nursing 2006. 55: 79-89.

24. Tinubu, BMS. Mbada, CE. Oyeyemi, AL and Fabunmi, AA. Work-Related Musculoskeletal Disorders among Nurses in Ibadan, South-west Nigeria: a cross-sectional survey. BMC Musculoskeletal Disorder. 2010. 11: 12.

25. Vieira, ER. Kumar, $S$ and Narayan, Y. Smoking, no-exercise, overweight and low back disorder in welders and nurses. International Journal of Industrial Ergonomics 2008. 38: 143:149.

26. Silverstein, BA. Fine, LJ and Armstrong, TJ. Occupational factors and carpal tunnel syndrome. American Journal of Industrial Medicine 1987. 11: 343-358.

27. Frymoyer, JW. Pope, MH and Costanza MC. Epidemiologic studies of low back pain. Spine 1980. 5: 419-423.

28. Daraiseh, N. Genaidy, AM. Karwowski, W. Davis LS. Stambough, $\mathrm{J}$ and Huston RI. Musculoskeletal outcomes in multiple body regions and work effects among nurses: The effects of stressful and stimulating working conditions. Ergonomics 2003. 46: 1178-1199.

29. Sahu S. Goswami S. and Ganguly R. Ergonomic Survey on Health Status of the Nurses Working in Shift in Hospitals. The Malyasian Journal of Nursing 2011. I2(3): 12-15. 